\title{
CD4+FOXP3+ regulatory T-cell subsets in human immunodeficiency virus infection
}

\author{
Federico Simonetta ${ }^{1,2,3}$ and Christine Bourgeois ${ }^{1,2}$ * \\ 1 INSERM, U1012, Le Kremlin-Bicêtre, France \\ 2 Université Paris-SUD, UMR-S1012, Le Kremlin-Bicêtre, France \\ ${ }_{3}^{3}$ Division of Immunology and Allergy, Department of Internal Medicine, Geneva University Hospitals, Geneva, Switzerland
}

\section{Edited by:}

Eyad Elkord, United Arab Emirates University, UAE; University of Salford, UK; University of Manchester, UK

Reviewed by:

Ana Izcue, Max Planck Institute of Immunobiology, Germany

Vigo Heissmeyer, German Research

Center for Environmental Health,

Germany

${ }^{*}$ Correspondence:

Christine Bourgeois, Institut National de la Santé et de la Recherche

Médicale (INSERM), U.1012, Faculté de Médecine du Kremlin-Bicêtre

Université PARIS-SUD, 63, rue Gabriel Péri, 94276 Le Kremlin Bicêtre,

France

e-mail: christine.bourgeois@u-psud.fr
The role of CD4+FOXP3+ regulatory T cells (Treg) in human immunodeficiency virus (HIV) infection has been an area of intensive investigation and remains a matter of ardent debate. Investigation and interpretation suffered from uncertainties concerning Treg quantification. Firstly, Treg quantification and function in HIV infection remain controversial in part because of the lack of reliable and specific markers to identify human Tregs. Secondly, analyzing Treg percentages or absolute numbers led to apparent discrepancies that are now solved: it is now commonly accepted that Treg are targets of HIV infection, but are preferentially preserved compared to conventional CD4 T cells. Moreover, the duality of immune defects associated to HIV infection, i.e., low grade chronic inflammation and defects in HIV-specific responses also casts doubts on the potential impact of Treg on HIV infection. Tregs may be beneficial or/and detrimental to the control of HIV infection by suppressing chronic inflammation or HIV-specific responses respectively. Indeed both effects of Treg suppression have been described in HIV infection. The discovery in recent years of the existence of phenotypically and functionally distinct human CD4+FOXP3+ Treg subsets may provide a unique opportunity to reconcile these contrasting results. It is tempting to speculate that different Treg subsets exert these different suppressive effects. This review summarizes available data concerning Treg fate during HIV infection when considering Treg globally or as subsets. We discuss how the identification of naive and effector Treg subsets modulates our understanding of Treg biology during HIV infection and the potential impact of HIV infection on mechanisms governing peripheral differentiation of adaptive Tregs.

Keywords: HIV, Treg, FOXP3, CD25

\section{INTRODUCTION}

CD4+FOXP3+ regulatory T cells (Treg) are a critical CD4 T-cell subset involved in the control of immune-tolerance by regulating immune-homeostasis and limiting immune-activation. Defects in Treg cell numbers or function have been related to the development of human autoimmune diseases, while increases in Treg numbers or activity could limit anti-tumoral immune-responses. In contrast to these two scenarios, in which beneficial or detrimental roles of Treg are easily predictable, a much more complex picture emerges for the role of Treg in infectious diseases. Treg mediated inhibition of antimicrobial immune-responses could lead to ineffective clearance of the pathogen contributing to the chronicization of the infection. On the other side, Treg participate to terminate immune-responses thus preventing exacerbated and potentially harmful immune-activation $(1,2)$. The impact of Treg during human immunodeficiency virus (HIV) infection is even more difficult to integrate due to the dual features of HIV infection. $\mathrm{HIV}$ infection is a chronic viral infection inducing drastic CD4 T-cell depletion that is associated with both immune deficiency and dysregulated chronic immune-activation. The control of viral replication is highly dependent on HIV-specific T-cell responses as revealed by the analysis of patients who spontaneously control the virus. Chronic inflammation sustains CD4+ T-cell decay and participates to loss of functional CD8 T-cell activity. Improving HIV-specific responses and limiting chronic immune inflammation are current goals of HIV therapies. Theoretically, Treg may suppress both chronic immune inflammation and HIV-specific responses being thus both beneficial and deleterious in HIV pathogenesis $(3,4)$. Whereas the dual role of Treg in the pathogenesis of HIV infection is now accepted, debates are still vivid to determine whether residual Treg exert these dual effects simultaneously or sequentially. Interestingly, Treg inhibition does not solely apply to immune functions, but also to the virus: Treg have also been described to directly inhibit HIV infection and replication. Finally additional complexity emerges from the observation that Treg may constitute a potent reservoir, thus leading to consider infected Tregs as an obstacle to efficient control of HIV infection. Determining the net impact of Treg cells on HIV infection remains a matter of ardent debate and face major hurdles: (a) Treg quantification during HIV infection remains controversial in part because of the lack of reliable and specific markers to identify human Treg; (b) expression of Treg quantification using percentages or absolute numbers led to obvious discrepancies that need to be discussed; (c) HIV infection recovers multiple immunological and viral status including patients during primary infection, chronically viremic patients, aviremic antiretroviral therapy (ART) treated patients 
or spontaneous controllers, which should be considered independently; (d) the accuracy of Treg analysis in the blood versus crucial sites such as lymph-node or gut associated mucosa is also under debate; (e) Treg have been essentially identified so far as a unique population whereas increasing evidence demonstrate high diversity in function and ontogeny. One may also question whether different Treg subsets may differently modulate HIV pathogenesis. Integrating Treg heterogeneity may prove crucial to dissect the impact of Treg mediated suppression during HIV infection. In the present review we will focus on Treg phenotypic and functional heterogeneity in order to elucidate Treg fate during HIV infection and to better delineate the protective or pathogenic roles of Treg cells in HIV infection.

\section{HIV INFECTION AND GLOBAL TREGS IDENTIFICATION STRATEGIES}

Firstly identified in 1995 in mice as a suppressive CD4 T-cell subset constitutively expressing the IL-2 receptor alpha-chain (CD25) molecule (5), Treg have been subsequently identified in humans as a CD4 T-cell subset exhibiting in vitro suppressive properties and expressing high levels of CD25 (6-10). Unfortunately, the inducible nature of CD25 expression during T-cell activation on conventional $\mathrm{T}$ cells renders this molecule unsuited for Treg identification during immune-activation. Shortly thereafter, the forkhead box P3 (FOXP3) transcription factor was identified as an essential and specific factor for Treg development and function (11-13). While FOXP3 is to date the most specific marker for Treg identification in mice, in humans the situation is more complex, as the expression of FoxP3 is also observed in some conventional CD4+ CD25-T cells upon activation (14). Finally, it has been shown that human CD4+FOXP3+CD25high cells express lower levels of CD127, the alpha-chain of the IL-7 receptor, when compared with their FOXP3-counterpart (15-17). The combination of the CD25 and CD127 surface markers with or without intra-nuclear staining for FOXP3 expression has thereafter been widely employed to identify CD4+ Treg cells (Figures 1A-C). Sorting of Treg cells has greatly benefited from the combination of high CD25 and low CD127 expression. However such an approach also presents drawbacks: conventional non-Treg CD4 $\mathrm{T}$ cells down-regulate CD127 expression during activation while they up-regulate CD25. It is therefore likely that CD127 and CD25 expression cannot accurately discriminate ex vivo Treg cells from activated T cells in situations of immune-activation such as HIV infection (18). In conclusion, Treg identification in context of chronic activation such as HIV infection, still suffers from the lack of indisputable markers that can unequivocally distinguish Treg from effector cells.

\section{TREG SUSCEPTIBILITY TO HIV INFECTION AND SUPPRESSIVE PROPERTIES}

Several studies have shown in vitro that Treg cells are highly susceptible to HIV infection (19-22). Moreover, Treg susceptibility seems to differ depending on the HIV type 1 strain, Treg being less susceptible to R5 viruses compared with effector T cells (22). Interestingly, Tran et al. suggested that Treg could represent a preferential cellular reservoir of viral infection (21). Treg suppressive capacity does not seem to be affected by HIV infection as Treg isolated from acutely $(23)$, chronically viremic $(24,49)$ infected patients, or HIV controllers $(24,49)$ suppress effector T cells proliferation as efficiently as Treg isolated from healthy donors.

\section{TREG QUANTIFICATION IN HIV INFECTION}

Regulatory T cells quantification in HIV infection remains controversial in part because of the aforementioned lack of homogeneous and reliable specific markers to identify human Tregs. A second hurdle arises from the strategy used to quantify Tregs. Because CD4 depletion is the pathogenic hallmark of HIV infection and CD4 counts decline during disease progression, determining Treg percentages among CD4 T cells or Treg counts does not provide similar information and thus participates to the uncertainties concerning Treg quantification. Both quantifications have their advantages and drawbacks. Percentages allow analyzing relative proportion of Tregs among CD4 T cells regardless the intensity of CD4 T-cell depletion associated to HIV infection. Conversely, Treg numbers allow evaluating potential bias in effector non-CD4 Tcell/Treg ratio since Treg suppression not only affects CD4 T cells but also effector CD8 T cells and innate cells. Interestingly, these two analyses led to different observations: Treg numbers are essentially reduced during HIV infection, but Treg are preferentially preserved compared to conventional CD4 T cells thus diversely impacting Treg percentages among CD4 T cells. Extreme care should be taken when interpreting these opposing data. Increasing Treg percentages among CD4 T cells suggest increasing Treg mediated suppression capacities against CD4 T cells, but reduced Treg numbers suggest reduced suppression capacity on other cellular targets (CD8 T cells, NK cells, dendritic cells). It thus seems relevant to provide both sets of information to finely dissect the global impact of Treg during HIV infection. Such particular feature of Treg alteration during HIV infection may provide an important rationale to understand diversity of Treg mediated effects. Finally, a third major aspect participating to the discrepancies obtained is represented by the diversity of HIV clinical stages rendering universal conclusion difficult to be drawn. Exhaustive analyses addressing the different immunological and virological status of HIV patients finally allowed some consensual conclusions to be formulated. During primary HIV infection (PHI), decreased Treg percentages $(23,25,26)$ and absolute numbers (26) have been described, although results differ depending on the staining strategy (25). In chronically infected viremic patients, Treg percentages are shown to be consistently increased while Treg absolute numbers consistently decreased (24, 26-35). During efficacious ART Treg percentages have been shown to progressively decrease to normal levels $(33,36-40)$ while Treg counts increase progressively in parallel with total CD4 counts $(24,33,37-39,41)$. Interestingly this effect is reversed upon ART interruption (42). Studies of Treg levels in HIV controllers, a subpopulation of patients who spontaneously control viral loads (43), revealed alternately unchanged $(20,24,39,44)$, increased $(45)$, or reduced $(26,46)$ percentages compared to healthy donors. Treg absolute numbers have been reported to be either unchanged (39) or decreased (26) in HIV controllers compared to healthy individuals. Importantly, analyses of Treg homeostasis were also performed apart from peripheral blood and notably in gastrointestinal mucosa which represents a major site of viral replication and CD4 T-cell depletion, and thus 

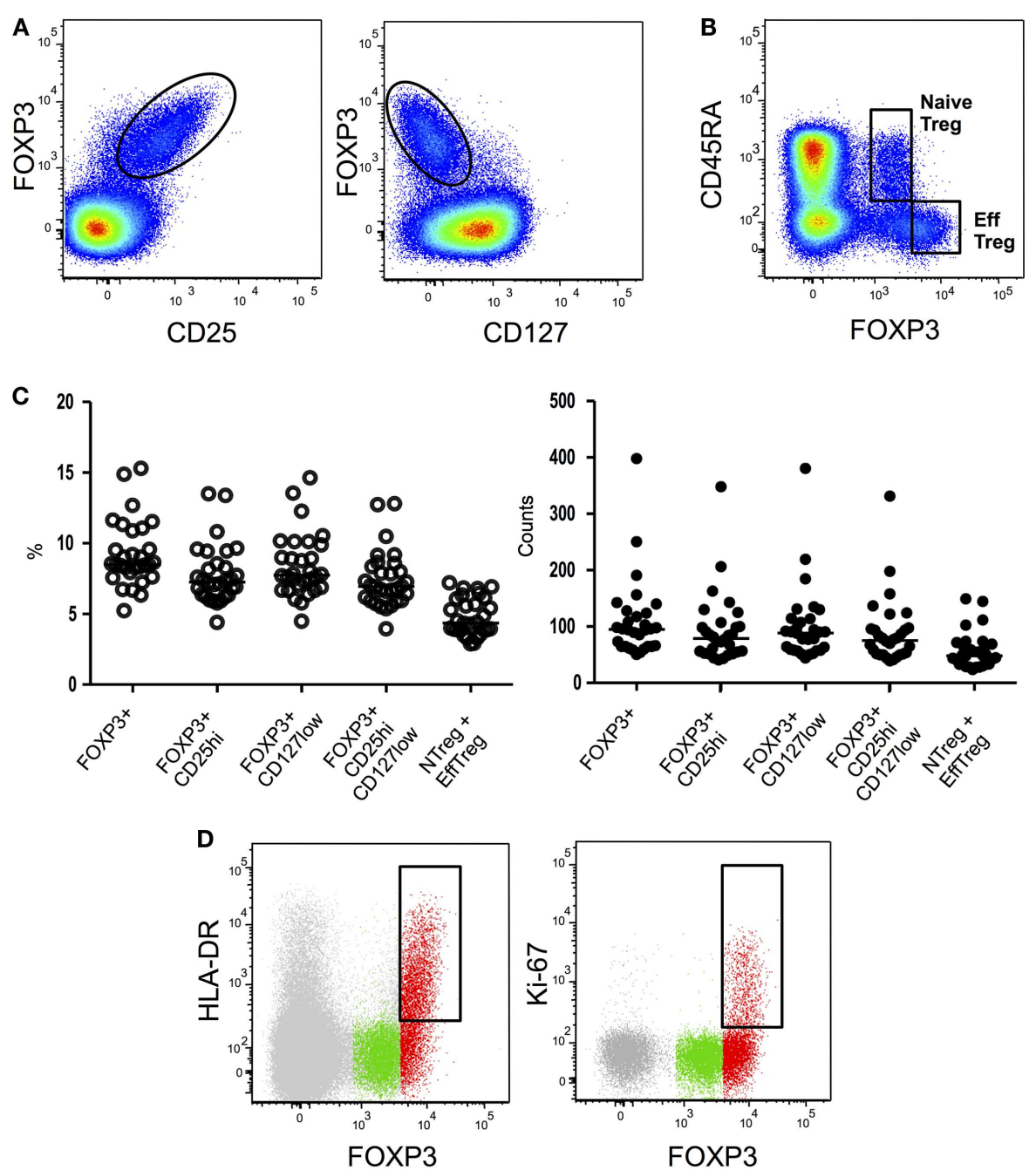

FIGURE 1 | Flow cytometryidentification strategies of Treg subsets. (A) Global Treg identification based on FOXP3, CD25, and CD127 expression by CD4T cells. (B) Expression of CD45RA and FOXP3 by CD4T cells allows the identification of CD45RA+ FOXP3low resting or naïve Treg and CD45RA- FOXP3high activated or effector Treg. (C) Treg proportions and absolute numbers obtained employing different existing gating strategies. (D) Further identification of effector Treg subsets based on HLA-DR or Ki67 expression. HLA-DR or Ki67 expression in global CD4 T cells (gray), CD45RA+ FOXP3low naïve Treg (green), or CD45RAFOXP3high effector Treg (red) is shown. represents a central site involved in HIV infection pathogenesis. Few studies investigating Treg levels in the intestinal tract demonstrated that during viremic HIV infection a global CD4 T-cell loss takes place in gastrointestinal mucosa with preferential preservation of Treg, leading to a relative increase in Treg proportion (24, 47-49). Such a process is reversed by efficient ART during which restoration of normal Treg levels in gastrointestinal tract is observed $(24,47-49)$. Collectively, data obtained from intestinal tract thus corroborated data obtained from peripheral blood showing a reduction of Treg numbers in peripheral blood and gut mucosa during viremic stages, although Tregs appeared preferentially preserved among CD4 T cells at both sites.

\section{IMPACT ON HIV PROGRESSION}

Several studies tried to evaluate in vivo Treg role on HIV infection by correlating Treg percentages or numbers to different canonical parameters of HIV disease, i.e., CD4 count, viral load, and activation profile. Most of published studies agree in reporting a positive correlation between absolute numbers of Treg and CD4 counts $(26,28,31,37,39,50-54)$ and a negative correlation between Treg percentages and CD4 counts $(27,29,31,34,37$, $39,55,56)$. One may discuss the relevance of correlation between CD4 counts and Treg counts because Treg are a CD4 T-cell subset. Interpretations were thus mostly drawn from correlation with viral load and/or activation profile. Viral load has been reported mostly to be positively correlated to Treg percentages $(29,39$, $40,55,57)$ and negatively correlated with Treg numbers (31, 39, $51,58)$. These observations led to investigate a direct impact of Treg on HIV-specific CD4 and CD8 T-cell responses. It has been shown that presence of CD4+ CD25+ cells during in vitro HIVspecific stimulation led to decreased HIV-specific CD4 and CD8 responses $(20,21,23,50,51,59-66)$. Importantly, Treg have been 
reported to suppress both cell proliferation and effector molecules production in response to HIV. Recently, Elahi and coworkers reported the interesting finding that Treg cells differentially suppress HIV epitope proliferation of CD8+ CTLs depending on HLA alleles restriction, epitope-specific CD8+ CTLs restricted to the protective HLA allele groups HLA-B $* 27$ and HLA-B $* 57$ being not susceptible to Treg mediated suppression (63). Collectively, published results suggest that a dominant mechanism of suppression by Treg could reduce in vivo antiviral responses participating to the incapacity to eradicate HIV infection. However, ex vivo correlation studies failed to detect any association between global Treg levels and HIV-specific T-cell responses in terms of IFN gamma (IFN- $\gamma$ ) production in response to HIV peptides stimulation $(24,40,44,51)$ or HIV-specific CD8 T-cell activation (26).

Immune hyper-activation as revealed by expression of CD38 and HLA-DR activation markers at CD4 and CD8 cell surface is a negative prognostic factor associated with disease progression in HIV infection $(67,68)$. In order to investigate if Treg alteration played a role in this phenomenon, several studies have tried to identify a correlation between Treg level and lymphocytes activation. Unfortunately no clear conclusion can be drawn using expression of CD38 and HLA-DR expression analyses to evaluate CD4 and CD8 activation. Conflicting results have been reported concerning relationship of Treg with immune-activation in PHI depending on Treg identification strategy employed (23, 69). Similarly, no consensus has been reached in studies including patients during chronic viremic infection when either positive $(29,53)$, negative $(25,51,70)$, or no correlations $(32,55)$ between Treg levels and immune-activation have been reported. The only stage of infection in which some conclusion can eventually be reached is represented by aviremic patients undergoing ART in which several studies concluded for an inverse correlation between Treg proportions and T-cell activation $(36,42)$. Based on these observations some authors speculated that Treg could be sufficient to control low residual T-cell activation in ART-treated patients, but insufficient to affect generalized immune-activation observed during primary or chronic viremic HIV infection (4). In this hypothesis, restoring Treg pool in ART-treated patients may thus constitute an interesting strategy ensuring Treg suppression without affecting viral load control. IL-2 recombinant injection induces significant increase in Treg numbers (111) although no clinical benefits were observed from restoration of Treg pools, casting doubts on the relevance of Treg compartment on the control of immune-activation (71). However, the Treg subsets preferentially increased upon IL-2 treatment are not fully characterized. It could be useful to consider manipulation of specific Treg subsets to provide beneficial impact. Collectively, these contrasting results reinforce the notion that Treg could be a double edged sword during HIV infection. On one side, they are detrimental as they inhibit HIV-specific immune response. On the other side, they could participate to the maintenance of immune-homeostasis by reducing non-specific chronic immune hyper-activation. Taking into account Treg heterogeneity may prove crucial to dissect these opposite effects of Treg mediated suppression during HIV infection.

\section{HIV INFECTION AND TREGS SUBSETS}

Similarly to other T-cells compartments, Treg population presents a high degree of heterogeneity both in humans and mice. Several markers allow the identification of phenotypically distinct Treg subsets, and controversies exist about which Treg subpopulations present peculiar functional characteristics. As described for conventional T cells, distinction between naïve and effector cells have been considered for Treg subsets. CD45RA or CD45RO expression has been notably considered to identify naïve and effector Tregs. Such strategy offers interesting insight on the biology of Tregs in HIV infection as discussed below, being an initial step that partially reflects the heterogeneity among Treg subsets. Other markers, such as HLA-DR or Inducible costimulatory molecule (ICOS), have been reported to identify cells at other stages of activation and, more importantly, seem to identify peculiar Treg cell subsets provided with specific mechanisms and effects of suppression. Finally, some molecules implicated in Treg suppressive function, such as CD39 and Glycoprotein A repetitions predominant (GARP), are employed to identify peculiar Treg subsets. Defining additional markers and/or combination will undoubtedly allow further refining of Treg subsets preservation during the course of HIV infection. Identification of Treg subsets using activation markers and their respective impact on HIV infection will be briefly presented when information is available.

\section{SUBDIVISION IN NAÏVE AND EFFECTOR TREG SUBSETS}

Several studies have shown that CD45RA is an extremely useful marker for Treg identification when combined to CD25 (72, $73,110)$ or FOXP3 (74). CD45RA expression allows the repartition of the FOXP3 + CD4 T-cell population in three subsets: (i) FOXP3low CD25low CD45RA+ cells, (ii) FOXP3high CD25high CD45RA - cells, and (iii) a FOXP3low CD25low CD45RA- population (74) (Figures 1B,C). FOXP3low CD25low CD45RA+ cells represents in human peripheral blood approximately 2$4 \%$ of CD4 T cells and $20-30 \%$ of "global" CD4+ FOXP3+ CD25high CD127low T cells. Accordingly to their "naïve" phenotype, CD45RA+ FOXP3low CD25low Tregs constitute the great majority of CD25 or FOXP3 expressing CD4 T cells in cord blood $(73,74)$. In classical in vitro suppressive assays CD45RA+ FOXP3low naïve Treg cells efficiently suppress effector T-cell proliferation (74). Interestingly during activation these cells actively proliferate, are highly resistant to apoptosis and convert to a CD45RA-CD45RO+ phenotype (74). It is important to note that early studies of human Treg based on the CD25high gating strategy initially proposed by Bacher-Allen $(6,75)$ inadvertently excluded the CD25low naïve Treg population from the analysis.

CD45RA - FOXP3 + CD4 + T cells include as mentioned two phenotypically and functionally distinct cellular subpopulations: (i) a FOXP3low CD25low CD45RA- cytokine-secreting cell population which lacks suppressor activity (ii) a suppressive effector FOXP3high CD25high CD45RA - Treg population (74). Such an analysis presents the major advantage of allowing the exclusion of the FOXP3+ non-Treg contaminating cells, which are included when the classical FOXP3 + CD25hi CD127low gating strategy is employed. FOXP3high CD25high CD45RA- effector Treg efficiently suppress conventional effector $\mathrm{T}$-cell responses in vitro 
but, in contrast to CD45RA+ naïve Treg, are highly susceptible to apoptosis and mostly die while exerting their suppressive function (74). CD45RA+ naïve Treg are able to differentiate into FOXP3high CD25high CD45RA- effector Treg upon in vitro and in vivo activation (74). However, whether the FOXP3high CD25high CD45RA - effector Treg pool is entirely represented by activated thymic derived Treg or can be composed by peripherally differentiated induced Treg (iTreg) still remains unknown.

\section{CD45RA+FOXP3low naïve Treg cells}

CD45RA+ FOXP3low CD25low Treg counts have been reported to be significantly reduced in HIV-infected patients when compared with healthy donors $(26,76)$. When different HIV diseases stages are taken into account naïve Treg counts reduction seems to be exclusively restricted to the PHI phase, while no difference is observed when viremic and aviremic chronically infected patients are considered (26). The majority of naïve CD45RA+ FOXP3low CD25low Treg also express CD31 (platelet endothelial cell adhesion molecule-1, PECAM-1), a cell surface marker identifying recent thymic emigrants. Proportions of CD31+ among naïve Treg are not affected during acute or chronic HIV infection indicating preserved Treg thymic differentiation (77). Naïve Treg express high levels of the HIV co-receptor CXCR4 while CCR5 is barely detectable at their surface (76-78). In vitro experiments have demonstrated that CD45RA+ naïve Treg are more susceptible to HIV infection when compared to conventional CD45RA+ naïve CD4 T cells $(76,78)$. Accordingly to their phenotype naïve Treg were more susceptible to in vitro infection when CXCR4-tropic strain (HIV-1 IIIB) was used rather than CCR5-tropic strain using HIV-1 BaL (76).

Regarding the association of naïve Treg cell numbers and parameters of disease in HIV infection, naïve Treg cell numbers positively correlate with CD4 count in both healthy donors and $\mathrm{HIV}$-infected patients $(26,31,76)$ independently from the stage of the disease. No association (76) or only weak inverse correlation $(26,31)$ between levels of HIV RNA levels and number of naive Tregs have been reported. Finally, naïve Treg cell numbers correlate neither with global CD8 T-cell activation nor with HIV-specific CD8 T-cell responses (26).

Globally, current evidence indicates that naïve Treg subset is minimally affected during HIV infection being altered exclusively during early phases of infection (primary infected patients). Ex vivo correlation analyses indicate only marginal role of naïve Treg on HIV infection.

\section{CD45RO+ FOXP3high CD25high effector Treg cells}

No differences $(26,76)$ or increase $(77)$ were reported in proportions of effector Treg among CD4 T cells during viremic chronic infection. In contrast, viremic chronically HIV-infected patients present a significant reduction in effector Treg cell counts when compared with healthy donors $(26,76)$, and this phenomenon was observed in other settings of disease including patients during PHI, aviremic patients under antiretroviral treatment, and HIV controllers (26). Therefore, effector Treg depletion appears to take place early during HIV infection and to persist during chronic phases of infection, while ART seems not to be able to restore the effector Treg pool. However, further studies analyzing cohorts followed up longitudinally may be needed to determine the effects of ART on reconstitution of the effector Treg subset. Accordingly to its expression on recent thymic emigrants, CD31 is barely detectable at effector Treg surface (74). Interestingly, Zhou and coworkers showed increased proportions of CD31 expressing effector Treg in both acutely and chronically HIV-infected patients suggesting higher conversion from a naïve to an effector Treg phenotype during HIV infection (77).

Phenotypic analysis of effector Treg revealed high levels of expression of the HIV co-receptor CCR5 while CXCR4 is expressed at lower levels at effector Treg surface when compared to naïve Treg cells $(76,77)$. Such a differential pattern of HIV co-receptor expression between naïve and effector Treg cells suggests potential differences in viral strains infection susceptibility. Indeed, effector Treg were more susceptible than naïve Treg to in vitro HIV infection by CCR5-tropic HIV-1 BaL while naïve and effector Treg were similarly susceptible to CXCR4-tropic HIV-1 IIIB in vitro infection (76).

Some conclusions can be drawn from correlation analyses regarding the role played by effector Treg in HIV infection. Effector Treg numbers positively correlate with CD4 counts in healthy donors and such a correlation is lost in chronically HIV-infected individuals $(26,76)$ presumably reflecting a preferential loss of the effector Treg subset. Lack of correlation between effector Treg numbers and CD4 counts was similarly found in patients during PHI and in individuals under efficacious ART (26), suggesting an early impairment in effector Treg homeostasis during HIV infection which is not restored by ART. Interestingly, the correlation was observed in HIV controllers, indicating a preserved effector Treg pool in this peculiar patient population. No correlation between effector Treg counts and HIV viral load $(26,76)$ or global CD8 Tcell activation (26) has been reported. Aiming to determine the role of effector Treg in modulation of HIV-specific immune-responses, we found an inverse correlation between effector Treg counts and both HIV-specific CD8 activation and interferon gamma production by CD8 upon stimulation by HIV peptides (26). These ex vivo results suggest a dominant suppression exerted by Treg on HIV-specific CD8 T-cell responses potentially participating to the incapacity to control the virus. Globally, available data indicate a preferential, precocious, and long-lasting effect of HIV infection on the effector Treg compartment. Analyses of association between Treg subsets and HIV disease parameters, while failing to detect any potential link with the naïve Treg subset, point to a deleterious effect of effector Treg in HIV infection pathogenesis. Further studies will eventually confirm the dominant suppressive role exerted by effector Treg on HIV-specific immuneresponses currently suggested by observational data. Surprisingly, no or low correlation was detected between Treg and immuneactivation so far. One may discuss the accuracy of the immune markers selected to determine such association. Secondly, specificity of effector Treg cells recovered during HIV infection also introduces heterogeneity. Demonstrating whether residual effector Treg are specifically targeting HIV related epitopes may further ascertain or infirm the specific role of Treg on HIV-specific responses.

\section{ADDITIONAL SUBDIVISION AMONG EFFECTOR TREGS}

Although highly altered in numbers by HIV infection, effector Tregs recovered from HIV-infected patients exhibited various 
phenotypic profiles. The relative susceptibility to HIV infection of each effector Treg subsets and their respective suppressive capacity remains to be further elucidated.

\section{HLA-DR}

MHC-II expression identifies a population that represents about $20-30 \%$ of human circulating Treg cells $(6,79)$. Ex vivo isolated HLA-DR+ Treg cells suppress responder T-cell proliferation and cytokine secretion more efficiently and more rapidly than HLA-DR-Treg cells (79). Importantly, all HLA-DR+ Treg cells are part of the effector FOXP3highCD45RA - compartment (74) (Figure 1D) of which they seem to constitute a terminally differentiated subset [reviewed in (80)].

Little is known about the effects of HIV infection on HLA-DR+ terminally effector Tregs or about the role exerted by this subset in the pathophysiology of the disease. Higher proportions of HLADR expressing Treg are present in chronically viremic HIV-infected patients when compared to healthy donors $(81,82)$ and Treg from patients presenting higher viral loads express higher levels of HLADR (81). ART fails to normalize HLA-DR+ Treg proportions (82). Unfortunately, no information about HLA-DR + terminally effector Treg counts is available and further studies may be needed to determine whether the reported alterations merely reflect a phenotypic modification linked to the activation status or whether HIV infection directly alters HLA-DR+ terminally effector Treg homeostasis. Correlation analysis demonstrated an inverse correlation between proportions of HLA-DR+ Tregs and CD4 counts $(81,83)$, while a positive correlation was reported between percentages of HLA-DR positive cells among Treg and viral load (83) or CD4 and CD8 T-cell activation as revealed by HLA-DR or CD38 expression (81). Once more it is currently impossible to ascertain whether these relationships simply reflect HLA-DR up-regulation at Treg surface as a result of the global immune-activation observed during HIV or identify terminal effectors HLA-DR+ Treg as players in HIV physiopathology.

\section{Ki67}

Intracellular Ki67 staining identifies an actively proliferating fraction of Treg cells. In both mice and humans the percentage of Ki67 cells among FOXP3 + cells is higher than the percentage among conventional FOXP3- CD4 T cells (84). This is in accordance with their more activated profile. Notably, all cycling Ki67+ Treg cells are part of the effector FOXP3highCD45RA - compartment (74) (Figure 1D). During HIV infection, higher proportions of Ki67+ Treg are present during acute (77) and chronic viremic (33, 77, $83,85)$ phases of infection. Longitudinal studies indicate that ART leads to normalization of Ki67+ Treg percentages $(77,83)$. Long term non-progressors present similar proportions of Ki67+ Treg as healthy donors (83) while no data are available in HIV controllers. Higher proportions of Ki67+ Treg seem to be associated with disease progression during chronic HIV infection as percentages of Ki67+ Treg correlate negatively with CD4 counts $(33,83)$ and positively with viral loads $(33,83)$. Collectively, higher levels of Ki67+ Treg have been associated with more advanced disease although studies addressing Ki67+ Treg counts and eventually analyzing HIV controllers could provide further insights into the role of this Treg subset in HIV physiopathology.

\section{OTHER SUBSETS}

\section{CD39}

CD39, also referred to as ENTPD-1, is a member of the ectonucleotidase triphosphate diphosphohydrolase family which hydrolyzes extracellular ATP and adenosine diphosphate (ADP) into adenosine monophosphate (AMP). Through CD39, Tregs can generate the inhibitory molecule adenosine which suppresses effector $\mathrm{T}$ cells by binding to the adenosine receptor $2 \mathrm{~A}$ at their surface (86). While murine Treg mice globally express CD39 at their surface $(86,87), \mathrm{CD} 39$ expression in human Treg is restricted to a subset of CD45RO expressing cells mostly co-expressing HLADR (87). Proportions of CD39+ Treg are significantly increased in HIV-infected patients, included chronic viremic patients, antiretroviral treated individuals, and long term non-progressors (39, $65,82)$. Interestingly, HIV controllers present proportions of CD39+ Treg similar to healthy donors (39). Longitudinal analysis confirmed that antiretroviral treatment fails to normalize proportions of CD39+ Treg (39). In vitro suppression assays revealed that the suppressive effect of Treg on cytokines production of Gag-stimulated CD8 $+\mathrm{T}$ cells is partially reversed by the addition of CD39 blocking mAb (65), pointing to a role for CD39 in Treg suppression of HIV-specific responses. Interestingly, CD39 is also involved in Treg control of HIV viral replication (64). CD39 expression on Treg correlates negatively with CD4+ T-cell count and positively with viral load and T-cell activation in HIV-1 positive subjects $(39,65)$. Globally, current evidence points to a major role for CD39 expression on Treg, participating to Treg mediated suppression of HIV-specific responses and disease progression.

\section{Inducible costimulatory molecule}

Inducible costimulatory molecule is a costimulatory molecule involved in cell activation that is expressed on effector/memory T-cell subsets. In mice, ICOS represents an activation marker at the Treg surface. Ex vivo, its expression identifies a sizable population which represent about $10-20 \%$ of CD4+FOXP3+ T cells isolated from secondary lymphoid organs. Whether ICOS expression exerts any function in Treg activity is still unknown. In humans differential expression of ICOS has been shown to delineate two different subsets of Treg cells in the peripheral blood (88). Interestingly, these two phenotypically distinct subsets present differences in their suppressive capacity and in the mechanisms of action employed: ICOS- Treg suppression is mainly mediated by TGF- $\beta$ while ICOS + Treg suppression relies predominantly on IL-10 (88). Higher proportions of ICOS expressing Treg have been reported in several populations HIV-infected patients, including viremic chronically infected patients, antiretroviral treated individuals, and HIV controllers (39). Longitudinal analysis revealed significant decrease of ICOS expressing Treg following ART treatment (39).

\section{Glycoprotein A repetitions predominant}

Glycoprotein A repetitions predominant (or LRRC32) is a transmembrane protein selectively expressed by activated Treg but not conventional CD4 T cells (89-91). Ex vivo, GARP identifies a subset of activated FOXP3 + T cells with high suppressive capacity. While barely expressed on CD45RA + naïve Treg, GARP is promptly up-regulated upon in vitro TCR-stimulation on both 
naïve and total Treg cells, while no expression is detected on activated conventional T cells (90). Moreover, human CD4 T cells in which FOXP3 expression was induced by activation in the presence of TGF- $\beta$ failed to express GARP, leading to the hypothesis that GARP could be employed to identify bona fide Tregs (90). Two studies comparing GARP+ Treg proportions in healthy donors and HIV-infected individuals, failed to detect any significant difference $(82,90)$. This result was in discordance with the increase in proportions of FOXP3 + CD4 T cells reported in the same studies, leading to the hypothesis that a portion of FOXP3 + T cells detected during HIV infection are possibly recently activated cells and/or iTreg. Further studies combining GARP expression with effector Treg and iTreg identification strategies will eventually clarify this issue.

\section{SUBDIVISION IN EXTRATHYMICALLY INDUCED OR ADAPTIVE TREGS}

In addition to their activation profile, Treg has also been dissected in two subsets: natural Tregs originating from the thymus and extrathymically iTregs or adaptive Tregs generated in the periphery under a variety of conditions through conversion from naïve conventional CD4+ cells. Several mechanisms have been implicated in induced Foxp3+ Treg (iTreg) peripheral generation, including cytokines (TGF- $\beta$, IL-2) and metabolic pathways (tryptophan metabolism, retinoic acid).

\section{EX VIVO ITREG IDENTIFICATION}

Ex vivo quantification of iTreg during HIV is limited by the unavailability of a specific marker for identification of bona fide iTreg. Several markers have been proposed for iTreg identification but their specificity in distinguishing natural thymic derived Treg from peripherally differentiated iTreg is still a matter of debate.

\section{Helios}

The transcription factor Helios, a member of the Ikaros transcription factor family, has been reported to be expressed by $100 \%$ of CD4+CD8-Foxp3+ thymocytes and about 70\% peripheral Foxp3+ T cells in mice and humans (92). Interestingly, murine or human naïve $\mathrm{T}$ cells acquiring Foxp3 expression upon in vitro TCR-stimulation in the presence of TGF- $\beta$ failed to express Helios, suggesting that absence of Helios expression could be employed to identify peripherally differentiated iTreg (92). However, subsequent reports showed that depending on the stimulation conditions, Helios could be induced in parallel with Foxp3 in iTreg (93-95). Moreover, Helios was reported to represent a T cell activation and proliferation marker thus being independent from Treg lineage commitment (96). Finally, natural Treg recent thymic emigrants have been shown to contain a fraction of Helios negative cells (97). Regardless its limited reliability as a maker differentiating nTreg from iTreg, Helios expression allows the identification of a subset of Treg cells presenting some peculiar characteristics. Murine Helios+ Treg express higher levels of CD103 and GITR at their surface and produce higher levels of TGF- $\beta$ (94). Interestingly, murine and human data indicate that Helios+ Treg are relatively over-represented in tumors, pointing to this cell subset as a potential target for immune-modulating strategies (94, $98,99)$. Currently, no information is available concerning Helios expression on Treg cells during HIV infection. Further studies will eventually define whether HIV infection differentially affects Helios+ and Helios - Treg subsets homeostasis and whether these subsets play a distinct role on HIV pathophysiology.

\section{Neuropilin-1}

Neuropilin-1 (NRP1) is a semaphorin III receptor participating in axon guidance, angiogenesis, and involved in the immunological synapse, which has been recently reported in mice to be expressed at high levels on thymic derived nTreg cells but not on peripherally generated iTreg $(100,101)$. Importantly, NRP1 expression remains stable on NRP1 positive or negative Treg subsets upon TCR mediated or lymphopenia induced cell activation and proliferation while environmental inflammatory stimuli have been shown to modulate NRP1 expression (101). Therefore, NRP1 expression has been suggested as a potential marker distinguishing nTreg from iTreg, at least in steady state conditions. Whether these results obtained in the murine system can be translated to human cells still remains to be addressed. In humans, NRP1 seems to be expressed exclusively by a subsets of lymphnode resident Treg subset (102) while Treg isolated from human peripheral blood fail to express significant levels of NRP1 (102, 103). One study performed in HIV infection assessed proportions of Neuropilin-1 expressing CD4 T cells and correlation with other Treg markers and failed to detect any significant difference between healthy donors and viremic or aviremic antiretroviral treated HIV+ patients (104).

\section{HIV INFECTION FAVORS PERIPHERAL TREG INDUCTION}

Numerous studies suggest an effect of HIV on iTreg cells generation mainly through modulation of antigen presenting cells (APC) tolerogenicity. Plasmacytoid dendritic cells (pDCs) represent a crucial subset of APC involved in antiviral immunity and a major target of HIV infection. Through Toll-like receptor 7 stimulation, HIV modulates pDC activation by simultaneously inducing type I IFN production and up-regulation of indoleamine 2,3 dioxygenase (IDO) expression $(105,106)$. IDO is an enzyme involved in tryptophan catabolisms which exerts immuno-modulatory functions by inhibiting T-cell proliferation and inducing iTreg peripheral generation. HIV-activated human $\mathrm{pDC}$ induce the peripheral generation of iTreg (106) through IDO up-regulation. Consequently, iTreg induced by HIV-activated pDC modulate myeloid dendritic cells (mDC) maturation and function partially through cytotoxic T-lymphocyte antigen (CTLA)-4 engagement, inhibiting their maturation and inducing IDO expression (106, 107). CTLA4-conditioned $\mathrm{mDC}$ can in turn induce Treg differentiation in an IDO-dependent manner (107). Whether HIV could directly modulate $\mathrm{mDC}$ capacity to generate iTreg still remains unclear. Lymph-node resident mDC from viremic but not ART-treated HIV-infected subjects induce iTreg differentiation phenotype of normal allogeneic T cells (108). Accordingly, preclinical data in the SIV infection model indicate that mature splenic or mesenteric $\mathrm{mDC}$ from SIV-infected animals are significantly more efficient at inducing Treg than $\mathrm{mDCs}$ from uninfected animals (82). However, experimental evidence indicates that in vitro infection of $\mathrm{mDC}$ with CCR5-utilizing virus or even simple exposure of $\mathrm{mDC}$ to inactivated HIV significantly impairs their ability to induce iTreg differentiation (109). 


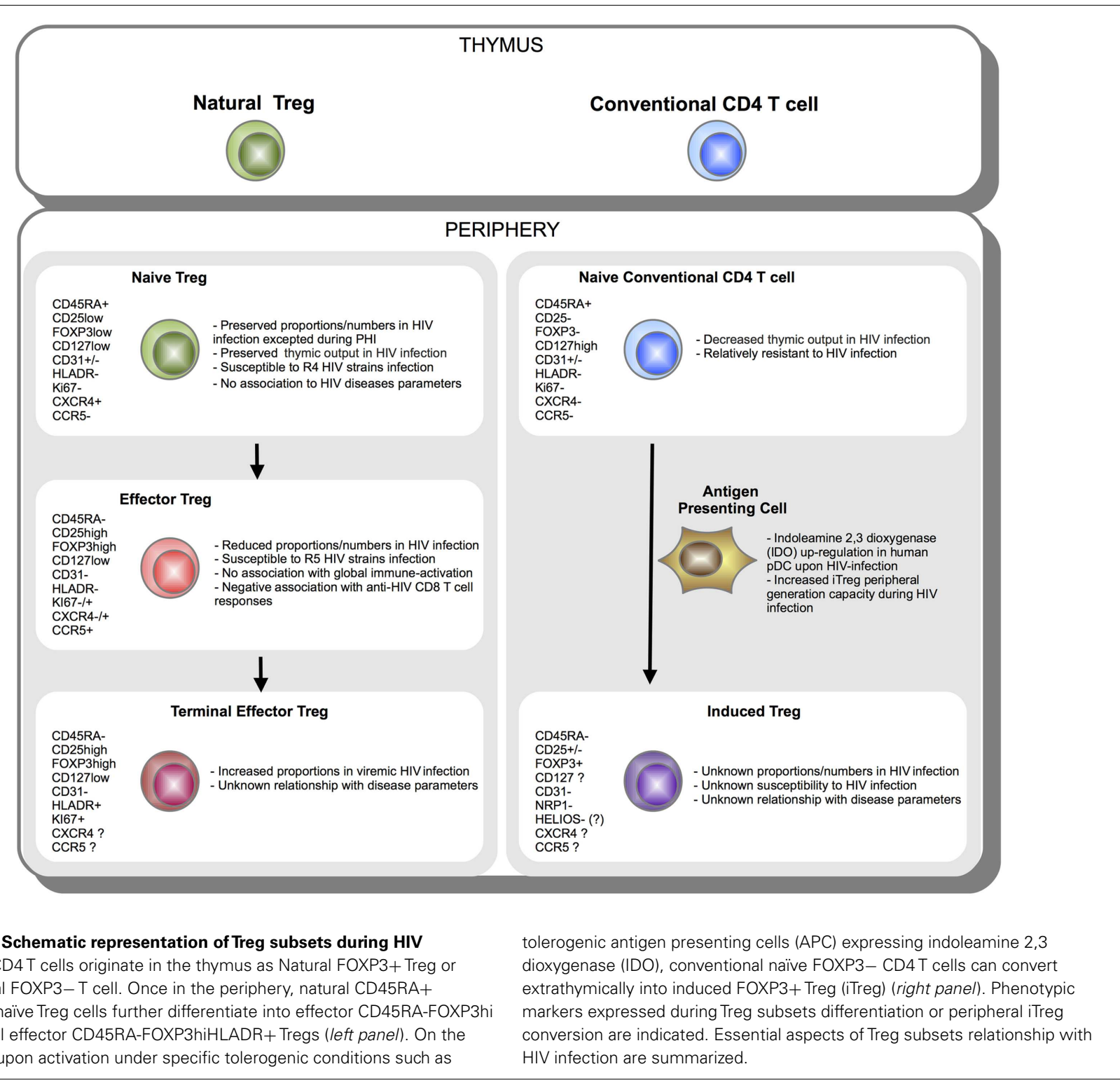

FIGURE 2 | Schematic representation of Treg subsets during HIV infection. CD4 T cells originate in the thymus as Natural FOXP3+ Treg or conventional FOXP3-T cell. Once in the periphery, natural CD45RA+ FOXP3low naïve Treg cells further differentiate into effector CD45RA-FOXP3hi and terminal effector CD45RA-FOXP3hiHLADR+Tregs (left pane/). On the other side, upon activation under specific tolerogenic conditions such as

\section{CONCLUDING REMARISS}

Human Treg quantification, especially in contexts of chronic immune-activation such as HIV infection, still remains uncertain essentially because of limitations in identification strategies. We discussed how dissecting Treg heterogeneity provided additional insights on the biology of Treg during HIV infection. A schematic representation of Treg subsets during HIV infection is provided in Figure 2. Currently two main strategies are used to classify and characterize Treg subsets. In accordance with classification established for conventional T cell, analyses of "naïve" and effector Tregs have been considered. Importantly, naïve and effector Treg discrimination led to better identification of Treg by limiting contamination by Foxp3low non-Treg cells. Use of classical markers of T-cell activation (CD45RA/RO, HLA-DR, Ki67, ICOS) or use of markers more specific to Treg subsets have been considered. Such distinction among naïve and effector Treg subsets allowed unveiling differences in HIV infection susceptibility and homeostatic behavior during HIV infection. We and others reported a preferential role for effector Treg compartment in immune-regulation during HIV infection. This two-step discrimination allows approaching Treg heterogeneity, but still remains incomplete. High heterogeneity presumably stands among effector cells and remains to be further investigated. A second classification is based on the identification of natural versus peripherally iTregs. Whereas understanding immune-regulation developing during HIV infection may be greatly improved from the precocious analysis of iTregs, the current lack of a reliable marker to identify these cells currently precludes consensual conclusions to emerge. Despite major advances in recent years, this is the early stage of Treg heterogeneity analysis in the context of HIV infection. Further studies will hopefully identify deleterious and beneficial Treg subsets and allow designing accurate restoration strategies to reduce chronic immune inflammation during HIV infection. 


\section{REFERENCES}

1. Belkaid Y. Role of Foxp3-positive regulatory $\mathrm{T}$ cells during infection. Eur J Immunol (2008) 38:918-21. doi:10.1002/eji.200738120

2. Belkaid Y, Tarbell K. Regulatory $\mathrm{T}$ cells in the control of host-microorganism interactions (*). Annu Rev Immunol (2009) 27:551-89. doi:10.1146/annurev. immunol.021908.132723

3. Imamichi H, Lane HC. Regulatory $\mathrm{T}$ cells in HIV-1 infection: the good, the bad, and the ugly. J Infect Dis (2012) 205(10):1479-82. doi:10.1093/infdis/jis238

4. Chevalier MF, Weiss L. The split personality of regulatory $\mathrm{T}$ cells in HIV infection. Blood (2013) 121:29-37. doi:10.1182/ blood-2012-07-409755

5. Sakaguchi S, Sakaguchi N, Asano $M$, Itoh $M$, Toda $M$. Immunologic self-tolerance maintained by activated $\mathrm{T}$ cells expressing IL2 receptor alpha-chains (CD25). Breakdown of a single mechanism of self-tolerance causes various autoimmune diseases. J Immunol (1995) 155:1151-64.

6. Baecher-Allan C, Brown JA, Freeman GJ, Hafler DA. CD4+CD25high regulatory cells in human peripheral blood. $J$ Immunol (2001) 167:1245-53.

7. Levings MK, Sangregorio R, Roncarolo MG. Human cd25(+)cd4(+) t regulatory cells suppress naive and memory $\mathrm{T}$ cell proliferation and can be expanded in vitro without loss of function. J Exp Med (2001) 193:1295-302. doi:10.1084/jem.193.11.1295

8. Ng WF, Duggan PJ, Ponchel F, Matarese G, Lombardi G, Edwards $\mathrm{AD}$, et al. Human CD4(+)CD25(+) cells: a naturally occurring population of regulatory T cells. Blood (2001) 98:273644. doi:10.1182/blood.V98.9.2736

9. Jonuleit H, Schmitt E, Stassen M, Tuettenberg A, Knop J, Enk AH. Identification and functional characterization of human CD4(+)CD25(+) T cells with regulatory properties isolated from peripheral blood. J Exp Med (2001) 193:1285-94. doi:10.1084/ jem.193.11.1285

10. Dieckmann D, Plottner H, Berchtold S, Berger T, Schuler G. Ex vivo isolation and characterization of CD4(+)CD25(+) $\mathrm{T}$ cells with regulatory properties from human blood. JExp Med (2001) 193:130310. doi:10.1084/jem.193.11.1303

11. Hori S, Nomura T, Sakaguchi S. Control of regulatory $\mathrm{T}$ cell development by the transcription factor Foxp3. Science (2003) 299:1057-61. doi:10.1126/science. 1079490

12. Fontenot JD, Gavin MA, Rudensky AY. Foxp3 programs the development and function of CD4+CD25+ regulatory $\mathrm{T}$ cells. Nat Immunol (2003) 4:330-6. doi: $10.1038 /$ ni904

13. Khattri R, Cox T, Yasayko S-A, Ramsdell F. An essential role for Scurfin in CD4+CD25+ T regulatory cells. Nat Immunol (2003) 4:337-42. doi:10.1038/ni909

14. Allan SE, Crome SQ, Crellin NK, Passerini L, Steiner TS, Bacchetta R, et al. Activation-induced FOXP3 in human $\mathrm{T}$ effector cells does not suppress proliferation or cytokine production. Int Immunol (2007) 19(4):345-54. doi:10.1093/ intimm/dxm014

15. Cox AL, Thompson SAJ, Jones JL, Robertson VH, Hale G, Waldmann $\mathrm{H}$, et al. Lymphocyte homeostasis following therapeutic lymphocyte depletion in multiple sclerosis. Eur J Immunol (2005) 35:3332-42. doi:10.1002/eji.200535075

16. Seddiki N, Santner-Nanan B, Martinson J, Zaunders J, Sasson S, Landay A, et al. Expression of interleukin (IL)-2 and IL-7 receptors discriminates between human regulatory and activated $\mathrm{T}$ cells. J Exp Med (2006) 203:1693-700. doi:10.1084/jem.20060468

17. Liu W, Putnam AL, Xu-Yu Z, Szot GL, Lee MR, Zhu S, et al. CD127 expression inversely correlates with FoxP3 and suppressive function of human CD4+ T reg cells. J Exp Med (2006) 203:170111. doi:10.1084/jem.20060772

18. del Pozo Balado M, del M, Leal M, Méndez Lagares G, Mata RC, López-Cortés LF, et al. Increased regulatory $\mathrm{T}$ cell counts in HIVinfected nonresponders to hepatitis B virus vaccine. J Infect Dis (2010) 202:362-9. doi:10.1086/ 653707

19. Oswald-Richter K, Grill SM, Shariat N, Leelawong M, Sundrud MS, Haas DW, et al. HIV infection of naturally occurring and genetically reprogrammed human regulatory T-cells. PLoS Biol (2004) 2:E198. doi:10.1371/journal.pbio.0020198

20. Chase AJ, Yang H-C, Zhang $H$, Blankson JN, Siliciano RF. Preservation of FoxP3+ regulatory $\mathrm{T}$ cells in the peripheral blood of human immunodeficiency virus type 1-infected elite suppressors correlates with low CD4+ T-cell activation. J Virol (2008) 82:830715. doi:10.1128/JVI.00520-08

21. Tran T-A, de Goër de Herve M-G, Hendel-Chavez H, Dembele B, Le Névot E, Abbed K, et al. Resting regulatory $\mathrm{CD} 4 \mathrm{~T}$ cells: a site of HIV persistence in patients on long-term effective antiretroviral therapy. PLoS ONE (2008) 3:e3305. doi:10.1371/ journal.pone.0003305

22. Moreno-Fernandez ME, Zapata W, Blackard JT, Franchini G, Chougnet CA. Human regulatory $\mathrm{T}$ cells are targets for human immunodeficiency Virus (HIV) infection, and their susceptibility differs depending on the HIV type 1 strain. J Virol (2009) 83:1292533. doi:10.1128/JVI.01352-09

23. Kared H, Lelièvre J-D, Donkova-Petrini V, Aouba A, Melica G, Balbo M, et al. HIVspecific regulatory $\mathrm{T}$ cells are associated with higher CD4 cell counts in primary infection. AIDS (2008) 22:2451-60. doi:10.1097/ QAD.0b013e328319edc0

24. Angin M, Kwon DS, Streeck H, Wen F, King M, Rezai A, et al. Preserved function of regulatory $\mathrm{T}$ cells in chronic HIV-1 infection despite decreased numbers in blood and tissue. J Infect Dis (2012) 205:1495-500. doi:10.1093/infdis/ jis236

25. Ndhlovu LC, Loo CP, Spotts G, Nixon DF, Hecht FM. FOXP3 expressing CD127lo CD4+ T cells inversely correlate with CD38+ $\mathrm{CD} 8+\mathrm{T}$ cell activation levels in primary HIV-1 infection. J Leukoc Biol (2008) 83:254-62. doi:10. 1189/jlb.0507281

26. Simonetta F, Lecuroux C, Girault I, Goujard C, Sinet M, Lambotte $\mathrm{O}$, et al. Early and long-lasting alteration of effector CD45RA()Foxp3(high) regulatory T-cell homeostasis during HIV infection. J Infect Dis (2012) 205:1510-9. doi: 10.1093/infdis/jis235

27. Tsunemi $S$, Iwasaki $T$, Imado $T$, Higasa S, Kakishita E, Shirasaka T, et al. Relationship of CD4+CD25+ regulatory $\mathrm{T}$ cells to immune status in HIV-infected patients. AIDS (2005) 19:879-86. doi:10.1097/01. aids.0000171401.23243.56

28. Montes M, Lewis DE, Sanchez C, Lopez de Castilla D, Graviss EA, Seas C, et al. Foxp3+ regulatory $\mathrm{T}$ cells in antiretroviralnaive HIV patients. AIDS (2006) 20:1669-71. doi:10.1097/01.aids. 0000238415.98194.38

29. Lim A, Tan D, Price P, Kamarulzaman A, Tan H-Y, James I, et al. Proportions of circulating $\mathrm{T}$ cells with a regulatory cell phenotype increase with HIV-associated immune activation and remain high on antiretroviral therapy. AIDS (2007) 21:1525-34. doi:10. 1097/QAD.0b013e32825eab8b

30. Rallón NI, López M, Soriano V, García-Samaniego J, Romero M, Labarga P, et al. Level, phenotype and activation status of CD4+FoxP3+ regulatory $\mathrm{T}$ cells in patients chronically infected with human immunodeficiency virus and/or hepatitis $C$ virus. Clin Exp Immunol (2009) 155:3543. doi:10.1111/j.1365-2249.2008. 03797.x

31. Tenorio AR, Martinson J, Pollard D, Baum L, Landay A. The relationship of T-regulatory cell subsets to disease stage, immune activation, and pathogenspecific immunity in HIV infection. J Acquir Immune Defic Syndr (2008) 48:577-80. doi:10.1097/ QAI.0b013e31817bbea5

32. Tenorio AR, Spritzler J, Martinson J, Gichinga $\mathrm{CN}$, Pollard RB, Lederman MM, et al. The effect of aging on T-regulatory cell frequency in HIV infection. Clin Immunol (2009) 130:298-303. doi: 10.1016/j.clim.2008.10.001

33. Bi X, Suzuki Y, Gatanaga H, Oka S. High frequency and proliferation of CD4+ FOXP3+ Treg in HIV-1-infected patients with low CD4 counts. Eur J Immunol (2009) 39:301-9. doi:10.1002/eji. 200838667

34. Piconi S, Trabattoni D, Gori A, Parisotto S, Magni C, Meraviglia $\mathrm{P}$, et al. Immune activation, apoptosis, and Treg activity are associated with persistently reduced CD4+ T-cell counts during antiretroviral therapy. AIDS (2010) 24:1991-2000. doi:10.1097/QAD. 0b013e32833c93ce

35. Favre D, Mold J, Hunt PW, Kanwar B, Loke P, Seu L, et al. Tryptophan catabolism by indoleamine 2,3-dioxygenase 1 alters the balance of $\mathrm{TH} 17$ to regulatory $\mathrm{T}$ cells in HIV disease. Sci Transl Med (2010) 2:32ra36. doi:10.1126/ scitranslmed.3000632

36. Marziali M, De Santis W, Carello R, Leti W, Esposito A, Isgrò A, et al. Tcell homeostasis alteration in HIV1 infected subjects with low CD4 T-cell count despite undetectable virus load during HAART. AIDS (2006) 20:2033-41. doi:10.1097/ 01.aids.0000247588.69438.fd

37. Jiao $\mathrm{Y}, \mathrm{Fu} J$, Xing $\mathrm{S}, \mathrm{Fu} \mathrm{B}$, Zhang Z, Shi $M$, et al. The 
decrease of regulatory $\mathrm{T}$ cells correlates with excessive activation and apoptosis of CD8+ T cells in HIV-1-infected typical progressors, but not in long-term nonprogressors. Immunology (2009) 128:e366-75. doi:10.1111/j.13652567.2008.02978.x

38. Montes M, Sanchez C, Lewis DE, Graviss EA, Seas C, Gotuzzo E, et al. Normalization of FoxP3(+) regulatory $\mathrm{T}$ cells in response to effective antiretroviral therapy. $J$ Infect Dis (2011) 203:496-9. doi: 10.1093/infdis/jiq073

39. Schulze Zur Wiesch J, Thomssen A, Hartjen P, Tóth I, Lehmann C, Meyer-Olson D, et al. Comprehensive analysis of frequency and phenotype of $\mathrm{T}$ regulatory cells in HIV infection: CD39 expression of FoxP3+ T regulatory cells correlates with progressive disease. $J$ Virol (2011) 85:1287-97. doi:10. 1128/JVI.01758-10

40. Zhuang Y, Wei X, Li Y, Zhao K, Zhang J, Kang W, et al. HCV coinfection does not alter the frequency of regulatory $\mathrm{T}$ cells or CD8+ T cell immune activation in chronically infected HIV+ Chinese subjects. AIDS Res Hum Retroviruses (2012) 28:1044-51. doi:10.1089/ AID.2011.0318

41. Gaardbo JC, Nielsen SD, Vedel SJ, Ersbøll AK, Harritshøj L, Ryder LP, et al. Regulatory $\mathrm{T}$ cells in human immunodeficiency virus-infected patients are elevated and independent of immunological and virological status, as well as initiation of highly active anti-retroviral therapy. Clin Exp Immunol (2008) 154:80-6. doi:10. 1111/j.1365-2249.2008.03725.x

42. Weiss L, Piketty C, Assoumou L, Didier C, Caccavelli L, DonkovaPetrini V, et al. Relationship between regulatory $\mathrm{T}$ cells and immune activation in human immunodeficiency virus-infected patients interrupting antiretroviral therapy. PLoS ONE (2010) 5:e11659. doi:10.1371/journal. pone.0011659

43. Lambotte O, Boufassa F, Madec Y, Nguyen A, Goujard C, Meyer L, et al. HIV controllers: a homogeneous group of HIV-1-infected patients with spontaneous control of viral replication. Clin Infect Dis (2005) 41:1053-6. doi:10.1086/ 433188

44. Owen RE, Heitman JW, Hirschkorn DF, Lanteri MC, Biswas HH, Martin JN, et al. HIV+ elite controllers have low HIV-specific T-cell activation yet maintain strong, polyfunctional T-cell responses. AIDS (2010) 24:1095-105. doi:10.1097/QAD. 0b013e3283377ale

45. Brandt L, Benfield T, Mens $\mathrm{H}$, Clausen LN, Katzenstein TL, Fomsgaard A, et al. Low level of regulatory $\mathrm{T}$ cells and maintenance of balance between regulatory T cells and TH17 cells in HIV-1-infected elite controllers. J Acquir Immune Defic Syndr (2011) 57:101-8. doi:10.1097/ QAI.0b013e318215a991

46. Hunt PW, Landay AL, Sinclair E, Martinson JA, Hatano H, Emu B, et al. A low $\mathrm{T}$ regulatory cell response may contribute to both viral control and generalized immune activation in HIV controllers. PLoS ONE (2011) 6:e15924. doi:10. 1371/journal.pone.0015924

47. Epple H-J, Loddenkemper C, Kunkel D, Tröger H, Maul J, Moos V, et al. Mucosal but not peripheral FOXP3+ regulatory $\mathrm{T}$ cells are highly increased in untreated HIV infection and normalize after suppressive HAART. Blood (2006) 108:3072-8. doi:10.1182/blood-2006-04016923

48. Rueda CM, Velilla PA, Chougnet CA, Montoya CJ, Rugeles MT. HIV-induced T-cell activation/exhaustion in rectal mucosa is controlled only partially by antiretroviral treatment. PLOS ONE (2012) 7:e30307. doi:10. 1371/journal.pone.0030307

49. Shaw JM, Hunt PW, Critchfield JW, McConnell DH, Garcia JC, Pollard RB, et al. Increased frequency of regulatory $\mathrm{T}$ cells accompanies increased immune activation in rectal mucosae of HIVpositive noncontrollers. J Virol (2011) 85:11422-34. doi:10.1128/ JVI.05608-11

50. Kinter AL, Hennessey M, Bell A, Kern S, Lin Y, Daucher M, et al. $\mathrm{CD} 25(+) \mathrm{CD} 4(+)$ regulatory $\mathrm{T}$ cells from the peripheral blood of asymptomatic HIV-infected individuals regulate $\mathrm{CD} 4(+)$ and CD8(+) HIV-specific T cell immune responses in vitro and are associated with favorable clinical markers of disease status. J Exp Med (2004) 200:331-43. doi:10.1084/jem.20032069

51. Eggena MP, Barugahare B, Jones N, Okello M, Mutalya S, Kityo $\mathrm{C}$, et al. Depletion of regulatory $\mathrm{T}$ cells in HIV infection is associated with immune activation. J Immunol (2005) 174:4407-14.
52. Kolte L, Gaardbo JC, Skogstrand K, Ryder LP, Ersbøll AK, Nielsen SD. Increased levels of regulatory $\mathrm{T}$ cells (Tregs) in human immunodeficiency virus-infected patients after 5 years of highly active antiretroviral therapy may be due to increased thymic production of naive Tregs. Clin Exp Immunol (2009) 155:44-52. doi:10.1111/j. 1365-2249.2008.03803.x

53. Cao W, Jamieson BD, Hultin LE, Hultin PM, Detels R. Regulatory $\mathrm{T}$ cell expansion and immune activation during untreated HIV type 1 infection are associated with disease progression. AIDS Res Hum Retroviruses (2009) 25:18391. doi:10.1089/aid.2008.0140

54. Thorborn G, Pomeroy L, Isohanni H, Perry M, Peters B, Vyakarnam A. Increased sensitivity of CD4+ T-effector cells to CD4+CD25+ Treg suppression compensates for reduced Treg number in asymptomatic HIV-1 infection. PLoS ONE (2010) 5:e9254. doi:10.1371/ journal.pone.0009254

55. Zhang Z, Jiang Y, Zhang M, Shi W, Liu J, Han X, et al. Relationship of frequency of CD4+CD25+Foxp3+ regulatory $\mathrm{T}$ cells with disease progression in antiretroviral-naive HIV-1 infected Chinese. Jpn J Infect Dis (2008) 61:391-2.

56. He Y, Li J, Zheng Y, Luo Y, Zhou H, Yao Y, et al. A randomized case-control study of dynamic changes in peripheral blood Th17/Treg cell balance and interleukin-17 levels in highly active antiretroviraltreated HIV type 1/AIDS patients. AIDS Res Hum Retroviruses (2012) 28:339-45. doi:10.1089/AID.2011.0140

57. Loke P, Favre D, Hunt PW, Leung JM, Kanwar B, Martin JN, et al. Correlating cellular and molecular signatures of mucosal immunity that distinguish HIV controllers from noncontrollers. Blood (2010) 115:e20-32. doi:10.1182/ blood-2009-12-257451

58. Nilsson J, Boasso A, Velilla PA, Zhang R, Vaccari M, Franchini $\mathrm{G}$, et al. HIV-1-driven regulatory $\mathrm{T}$-cell accumulation in lymphoid tissues is associated with disease progression in HIV/AIDS. Blood (2006) 108(12):3808-17. doi:10. 1182/blood-2006-05-021576

59. Aandahl EM, Michaëlsson J, Moretto WJ, Hecht FM, Nixon DF. Human CD4+ CD25+ regulatory $\mathrm{T}$ cells control $\mathrm{T}$-cell responses to human immunodeficiency virus and cytomegalovirus antigens. J Virol (2004) 78:2454-9. doi:10.1128/JVI.78.5.2454-2459. 2004

60. Weiss L, Donkova-Petrini V, Caccavelli L, Balbo M, Carbonneil C, Levy Y. Human immunodeficiency virus-driven expansion of $\mathrm{CD} 4+\mathrm{CD} 25+$ regulatory $\mathrm{T}$ cells, which suppress HIV-specific CD4 T-cell responses in HIVinfected patients. Blood (2004) 104:3249-56. doi:10.1182/blood2004-01-0365

61. Legrand FA, Nixon DF, Loo CP, Ono E, Chapman JM, Miyamoto $\mathrm{M}$, et al. Strong HIV-1-specific T cell responses in HIV-1-exposed uninfected infants and neonates revealed after regulatory $\mathrm{T}$ cell removal. PLoS ONE (2006) 1:e102. doi:10.1371/journal.pone. 0000102

62. Kinter A, McNally J, Riggin L, Jackson R, Roby G, Fauci AS. Suppression of HIVspecific $\mathrm{T}$ cell activity by lymph node $\mathrm{CD} 25+$ regulatory $\mathrm{T}$ cells from HIV-infected individuals. Proc Natl Acad Sci U S A (2007) 104:3390-5. doi:10.1073/pnas.0611423104

63. Elahi S, Dinges WL, Lejarcegui N, Laing KJ, Collier AC, Koelle DM, et al. Protective HIV-specific CD8+ $\mathrm{T}$ cells evade Treg cell suppression. Nat Med (2011) 17:989-95. doi:10.1038/nm.2422

64. Moreno-Fernandez ME, Rueda CM, Rusie LK, Chougnet CA. Regulatory T cells control HIV replication in activated $\mathrm{T}$ cells through a cAMP-dependent mechanism. Blood (2011) 117:5372-80. doi:10. 1182/blood-2010-12-323162

65. Nikolova M, Carriere M, Jenabian M-A, Limou S, Younas M, Kök A, et al. CD39/adenosine pathway is involved in AIDS progression. PLoS Pathog (2011) 7:e1002110. doi:10.1371/journal.ppat.1002110

66. Méndez-Lagares G, Pozo-Balado MM, del Mar del Pozo Balado M, Genebat M, Genebat González M, García Pergañeda A, et al. Severe immune dysregulation affects CD4+CD25(hi)FoxP3+ regulatory $\mathrm{T}$ cells in HIV-infected patients with low-level CD4 T-cell repopulation despite suppressive highly active antiretroviral therapy. JInfect Dis (2012) 205:1501-9. doi:10.1093/infdis/jis230

67. Bouscarat F, Levacher-Clergeot M, Dazza MC, Strauss KW, Girard PM, Ruggeri C, et al. Correlation of CD8 lymphocyte activation with cellular viremia and plasma HIV RNA levels in 
asymptomatic patients infected by human immunodeficiency virus type 1. AIDS Res Hum Retroviruses (1996) 12:17-24. doi:10.1089/aid. 1996.12.17

68. Deeks SG, Kitchen CMR, Liu L, Guo H, Gascon R, Narváez $\mathrm{AB}$, et al. Immune activation set point during early HIV infection predicts subsequent CD4+ T-cell changes independent of viral load. Blood (2004) 104:942-7. doi:10. 1182/blood-2003-09-3333

69. Petitjean G, Chevalier MF, Tibaoui F, Didier C, Manea ME, Liovat A-S, et al. Level of double negative $\mathrm{T}$ cells, which produce TGF- $\beta$ and IL-10, predicts CD8 T-cell activation in primary HIV-1 infection. AIDS (2012) 26:139-48. doi:10.1097/ QAD.0b013e32834e1484

70. Prendergast A, Prado JG, Kang Y$H$, Chen F, Riddell LA, Luzzi G, et al. HIV-1 infection is characterized by profound depletion of CD161+ Th17 cells and gradual decline in regulatory $\mathrm{T}$ cells. AIDS (2010) 24:491-502. doi:10.1097/QAD. 0b013e3283344895

71. Abrams D, Lévy Y, Losso MH, Babiker A, Collins G, Cooper DA, et al. Interleukin-2 therapy in patients with HIV infection. NEngl J Med (2009) 361:1548-59. doi:10. 1056/NEJMoa0903175

72. Valmori D, Merlo A, Souleimanian NE, Hesdorffer CS, Ayyoub M. A peripheral circulating compartment of natural naive CD4 Tregs. J Clin Invest (2005) 115:1953-62. doi:10.1172/JCI23963

73. Fritzsching B, Oberle N, Pauly E, Geffers R, Buer J, Poschl J, et al. Naive regulatory $\mathrm{T}$ cells: a novel subpopulation defined by resistance toward CD95Lmediated cell death. Blood (2006) 108:3371-8. doi:10.1182/blood2006-02-005660

74. Miyara M, Yoshioka Y, Kitoh A, Shima $T$, Wing $K$, Niwa $A$, et al. Functional delineation and differentiation dynamics of human CD4+ $\mathrm{T}$ cells expressing the FoxP3 transcription factor. Immunity (2009) 30:899-911. doi:10. 1016/j.immuni.2009.03.019

75. Ashley CW, Baecher-Allan C. Cutting edge: responder $\mathrm{T}$ cells regulate human $\mathrm{DR}+$ effector regulatory $\mathrm{T}$ cell activity via granzyme B. J Immunol (2009) 183:4843-7. doi:10.4049/jimmunol.0900845

76. Arruvito L, Sabatté J, Pandolfi J, Baz P, Billordo LA, Lasala MB, et al. Analysis of suppressor and non-suppressor FOXP3+ $\mathrm{T}$ cells in HIV-1-infected patients. PLoS ONE (2012) 7:e52580. doi:10. 1371/journal.pone.0052580

77. Zhou H, Hao Y, Song C, Han J, Zhang J, Gao G, et al. Excessive conversion and impaired thymic output contribute to disturbed regulatory T-cell homeostasis in AIDS patients with low CD4 cell counts. AIDS (2013) 27(7):1059-69. doi:10.1097/QAD. 0b013e32835e2b99

78. Antons AK, Wang R, OswaldRichter K, Tseng M, Arendt CW, Kalams SA, et al. Naive precursors of human regulatory $\mathrm{T}$ cells require FoxP3 for suppression and are susceptible to HIV infection. J Immunol (2008) 180:764-73.

79. Baecher-Allan C, Wolf E, Hafler DA. MHC class II expression identifies functionally distinct human regulatory $\mathrm{T}$ cells. J Immunol (2006) 176:4622-31.

80. Sakaguchi S, Miyara M, Costantino CM, Hafler DA. FOXP3+ regulatory $\mathrm{T}$ cells in the human immune system. Nat Rev Immunol (2010) 10:490-500. doi:10.1038/nri2785

81. Xiao J, Qian K, Cao Q, Qiu C, Qiu C, Xue Y, et al. HLADR expression on regulatory $\mathrm{T}$ cells is closely associated with the global immune activation in HIV1 infected subjects naïve to antiretroviral therapy. Chin Med J (2011) 124:2340-6.

82. Presicce P, Orsborn K, King E, Pratt J, Fichtenbaum CJ, Chougnet CA. Frequency of circulating regulatory $\mathrm{T}$ cells increases during chronic HIV infection and is largely controlled by highly active antiretroviral therapy. PLoS ONE (2011) 6:e28118. doi:10. 1371/journal.pone.0028118

83. Xing S, Fu J, Zhang Z, Gao Y, Jiao Y, Kang F, et al. Increased turnover of FoxP3high regulatory $\mathrm{T}$ cells is associated with hyperactivation and disease progression of chronic HIV-1 infection. J Acquir Immune Defic Syndr (2010) 54:455-62. doi: 10.1097/QAI.0b013e3181e453b9

84. Vukmanovic-Stejic M, Zhang Y, Cook JE, Fletcher JM, McQuaid A, Masters JE, et al. Human CD4+ CD25hi Foxp3+ regulatory $\mathrm{T}$ cells are derived by rapid turnover of memory populations in vivo. J Clin Invest (2006) 116:2423-33. doi:10. 1172/JCI2894

85. Lim A, French MA, Price P. CD4+ and $\mathrm{CD} 8+\mathrm{T}$ cells expressing FoxP3 in HIV-infected patients are phenotypically distinct and influenced by disease severity and antiretroviral therapy. $J$ Acquir Immune Defic Syndr (2009) 51:248-57. doi:10.1097/QAI. 0b013e3181a74fad

86. Deaglio S, Dwyer KM, Gao W, Friedman D, Usheva A, Erat A, et al. Adenosine generation catalyzed by CD39 and CD73 expressed on regulatory $\mathrm{T}$ cells mediates immune suppression. J Exp Med (2007) 204:1257-65. doi:10.1084/ jem.20062512

87. Borsellino G, Kleinewietfeld $M$, Di Mitri D, Sternjak A, Diamantini A, Giometto $\mathrm{R}$, et al. Expression of ectonucleotidase CD39 by Foxp3+ Treg cells: hydrolysis of extracellular ATP and immune suppression. Blood (2007) 110:1225-32. doi:10.1182/ blood-2006-12-064527

88. Ito $\mathrm{T}$, Hanabuchi S, Wang Y$\mathrm{H}$, Park WR, Arima K, Bover $\mathrm{L}$, et al. Two functional subsets of FOXP3+ regulatory $\mathrm{T}$ cells in human thymus and periphery. Immunity (2008) 28:870-80. doi: 10.1016/j.immuni.2008.03.018

89. Wang R, Wan Q, Kozhaya L, Fujii H, Unutmaz D. Identification of a regulatory $\mathrm{T}$ cell specific cell surface molecule that mediates suppressive signals and induces Foxp3 expression. PLoS ONE (2008) 3:e2705. doi:10.1371/ journal.pone.0002705

90. Wang R, Kozhaya L, Mercer F, Khaitan A, Fujii H, Unutmaz D. Expression of GARP selectively identifies activated human FOXP3+ regulatory T cells. Proc Natl Acad Sci U S A (2009) 106:13439-44.

91. Tran DQ, Andersson J, Wang R, Ramsey H, Unutmaz D, Shevach EM. GARP (LRRC32) is essential for the surface expression of latent TGF-beta on platelets and activated FOXP3+ regulatory $\mathrm{T}$ cells. Proc Natl Acad Sci U S A (2009) 106:13445-50. doi:10. 1073/pnas.0901944106

92. Thornton AM, Korty PE, Tran DQ, Wohlfert EA, Murray PE, Belkaid Y, et al. Expression of Helios, an Ikaros transcription factor family member, differentiates thymic-derived from peripherally induced Foxp $3+\mathrm{T}$ regulatory cells. J Immunol (2010) 184:3433-41. doi:10.4049/jimmunol.0904028

93. Verhagen J, Wraith DC. Comment on expression of Helios, an Ikaros transcription factor family member, differentiates thymicderived from peripherally induced Foxp3+ T regulatory cells. J Immunol (2010) 185:7129; author reply 7130. doi:10.4049/jimmunol. 1090105

94. Zabransky DJ, Nirschl CJ, Durham NM, Park BV, Ceccato CM, Bruno TC, et al. Phenotypic and functional properties of Helios+ regulatory $\mathrm{T}$ cells. PLOS ONE (2012) 7:e34547. doi:10.1371/ journal.pone.0034547

95. Gottschalk RA, Corse E, Allison JP. Expression of Helios in peripherally induced Foxp3+ regulatory $\mathrm{T}$ cells. J Immunol (2012) 188:976-80. doi:10.4049/ jimmunol.1102964

96. Akimova T, Beier UH, Wang L, Levine MH, Hancock WW. Helios expression is a marker of $\mathrm{T}$ cell activation and proliferation. PLoS ONE (2011) 6:e24226. doi:10. 1371/journal.pone.0024226

97. Himmel ME, MacDonald KG, Garcia RV, Steiner TS, Levings MK. Helios+ and Helios- cells coexist within the natural FOXP3+ T regulatory cell subset in humans. $J$ Immunol (2013) 190:2001-8. doi: 10.4049/jimmunol.1201379

98. Elkord E, Sharma S, Burt DJ, Hawkins RE. Expanded subpopulation of FoxP3 $+\mathrm{T}$ regulatory cells in renal cell carcinoma coexpress Helios, indicating they could be derived from natural but not induced Tregs. Clin Immunol (2011) 140:218-22. doi:10.1016/j. clim.2011.04.014

99. Wainwright DA, Sengupta S, Han Y, Lesniak MS. Thymus-derived rather than tumor-induced regulatory $\mathrm{T}$ cells predominate in brain tumors. Neuro Oncol (2011) 13:1308-23. doi:10.1093/neuonc/ nor134

100. Yadav M, Louvet C, Davini D, Gardner JM, Martinez-Llordella $\mathrm{M}$, Bailey-Bucktrout $\mathrm{S}$, et al. Neuropilin-1 distinguishes natural and inducible regulatory $\mathrm{T}$ cells among regulatory $\mathrm{T}$ cell subsets in vivo. J Exp Med (2012) 209:1713-22, S1-19. doi:10.1084/ jem.20120822

101. Weiss JM, Bilate AM, Gobert M, Ding Y, Curotto de Lafaille MA, Parkhurst CN, et al. Neuropilin 1 is expressed on thymusderived natural regulatory $\mathrm{T}$ cells, but not mucosa-generated induced Foxp3+ T reg cells. J Exp Med (2012) 209:1723-1742,S1. doi:10. 1084/jem.20120914

102. Battaglia A, Buzzonetti A, Monego G, Peri L, Ferrandina G, Fanfani F, et al. Neuropilin1 expression identifies a subset of regulatory $\mathrm{T}$ cells in human lymph nodes that is modulated by 
preoperative chemoradiation therapy in cervical cancer. Immunology (2008) 123:129-38. doi:10.1111/j. 1365-2567.2007.02737.x

103. Milpied P, Renand A, Bruneau J, Mendes-da-Cruz DA, Jacquelin S, Asnafi V, et al. Neuropilin-1 is not a marker of human Foxp3+ Treg. Eur J Immunol (2009) 39:1466-71. doi:10.1002/eji.200839040

104. Lim AY-F, Price P, Beilharz MW, French MA. Cell surface markers of regulatory $\mathrm{T}$ cells are not associated with increased forkhead box p3 expression in blood CD4+ $\mathrm{T}$ cells from HIV-infected patients responding to antiretroviral therapy. Immunol Cell Biol (2006) 84:530-6. doi:10.1111/j. 1440-1711.2006.01467.x

105. Boasso A, Vaccari M, Hryniewicz A, Fuchs D, Nacsa J, Cecchinato $\mathrm{V}$, et al. Regulatory T-cell markers, indoleamine 2,3-dioxygenase, and virus levels in spleen and gut during progressive simian immunodeficiency virus infection.
J Virol (2007) 81:11593-603. doi: 10.1128/JVI.00760-07

106. Manches O, Munn D, Fallahi A, Lifson J, Chaperot L, Plumas J, et al. HIV-activated human plasmacytoid DCs induce Tregs through an indoleamine 2,3-dioxygenasedependent mechanism. J Clin Invest (2008) 118:3431-9. doi:10. 1172/JCI34823

107. Manches O, Fernandez MV, Plumas J, Chaperot L, Bhardwaj $\mathrm{N}$. Activation of the noncanonical NF- $\kappa$ B pathway by HIV controls a dendritic cell immunoregulatory phenotype. Proc Natl Acad Sci U S A (2012) 109:14122-7. doi:10.1073/pnas.1204032109

108. Krathwohl MD, Schacker TW, Anderson JL. Abnormal presence of semimature dendritic cells that induce regulatory $\mathrm{T}$ cells in HIVinfected subjects. I Infect Dis (2006) 193:494-504. doi:10.1086/ 499597

109. Presicce P, Moreno-Fernandez ME, Rusie LK, Fichtenbaum
C, Chougnet CA. In vitro HIV infection impairs the capacity of myeloid dendritic cells to induce regulatory $\mathrm{T}$ cells. PLOS ONE (2012) 7:e42802. doi:10.1371/ journal.pone.0042802

110. Seddiki N, Santner-Nanan B, Tangye SG, Alexander SI, Solomon $M$, Lee S, et al. Persistence of naive CD45RA+ regulatory $\mathrm{T}$ cells in adult life. Blood (2006) 107:2830-8. doi:10.1182/ blood-2005-06-2403

111. Weiss L, Letimier FA, Carriere $\mathrm{M}$, Maiella S, DonkovaPetrini V, Targat B, et al. In vivo expansion of naive and activated CD4+CD25+FOXP3+ regulatory $\mathrm{T}$ cell populations in interleukin-2-treated HIV patients. Proc Natl Acad Sci $\begin{array}{lllll}U & S & A & \text { (2010) 107:10632-7. }\end{array}$ doi:10.1073/pnas.1000027107

Conflict of Interest Statement: The authors declare that the research was conducted in the absence of any commercial or financial relationships that could be construed as a potential conflict of interest.

Received: 20 May 2013; accepted: 13 July 2013; published online: 30 July 2013.

Citation: Simonetta $F$ and Bourgeois $C$ (2013) CD4+FOXP3+ regulatory $T$ cell subsets in human immunodeficiency virus infection. Front. Immunol. 4:215. doi: 10.3389/fimmu.2013.00215

This article was submitted to Frontiers in Immunological Tolerance, a specialty of Frontiers in Immunology.

Copyright (C) 2013 Simonetta and Bourgeois. This is an open-access article distributed under the terms of the Creative Commons Attribution License (CC BY). The use, distribution or reproduction in other forums is permitted, provided the original author(s) or licensor are credited and that the original publication in this journal is cited, in accordance with accepted academic practice. No use, distribution or reproduction is permitted which does not comply with these terms. 